\title{
Psychosocial vulnerability of Mexican informal caregivers in fall-related hip fractures
}

\author{
Andrés Barragán-Rodríguez ${ }^{1 *}$, Manuel Gardea-Reséndez ${ }^{1}$, Omar Kawas-Valle$^{1}$, and \\ Víctor M. Peña-Martínez ${ }^{2}$ \\ ${ }^{1}$ Department of Psychiatry; ${ }^{2}$ Department of Orthopedics and Traumatology. "Dr. José E. González" University Hospital, Autonomous University of \\ Nuevo Leon, Monterrey, Nuevo Leon, Mexico
}

\begin{abstract}
Objective: The objective of the study was to assess the sociodemographic characteristics and caregiving abilities of informal caregivers of patients aged 65 years or older hospitalized for fall-related hip fractures. Material and methods: $A$ cross-sectional study was conducted with 51 relatives of patients with fall-related hip fractures in the Orthopedics Ward of the Dr. José E. González University Hospital in Monterrey, Mexico, from March 1, 2018, to February 28, 2019. Relatives were asked to answer a questionnaire with social, economic, and household questions, and a scale to measure the caregiving abilities of the caregivers. Results: The majority of informal caregivers were women (90.2\%), and their mean age was 50.39 years. Low educational level, insufficient sleep time, unemployment, and a monthly income equal to or below the minimum wage was frequently observed in both male and female caregivers. Analysis of the "Scale to Measure, the Caregiving Ability of Caregivers" suggests caregivers' confidence in their caring abilities. Caregivers' psychosocial profiles suggest that relatives may not be integrally prepared to shoulder the caregiving responsibility, putting both the patients and themselves at risk of complications. Conclusions: Training relatives for caregiving must be a priority in the attention of elders with fall-related hip fractures, due to the impact that this may have on the patient's rehabilitation process.
\end{abstract}

Key words: Comprehensive health care. Health of the elderly. Hip fractures. Caregiver. Accidental falls.

\section{Introduction}

The increasing incidence of fall-related hip fractures among the elderly has forced family members to adopt an unplanned role as informal caregivers. The rise in the number of hip fractures has been associated with the worldwide increase in life expectancy, especially in developed countries, and has become the most common cause of admission of the elderly to orthopedic units ${ }^{1}$. Although estimates on the annual prevalence of fall-related hip fractures in Mexican elders were $10-15 \%$ in
2005 , there is a lack of multicenter studies and national registries that provide a complete perspective of the current prevalence in our country ${ }^{2}$. While in $2015,8.6 \%$ of Mexico's population was 65 years or older, this number is expected to increase to $24.3 \%$ by $2050^{3}$. Estimations according to demographic changes in Mexico indicate that the annual number of hip fractures in 2050 will be five- to seven-fold higher than in 2005; hence, falls and hip fractures represent a growing public health concern ${ }^{4}$. In addition to the high mortality rate, up to $56 \%$ of older adults surviving hip fractures will have sustained

\section{Correspondence:}

*Andrés Barragán-Rodríguez

E-mail: andresbarragan.barragan@gmail.com
Available online: $17-03-2020$

Date of reception: 20-08-2019

Date of acceptance: 14-11-2019 DOI: 10.24875/RMU.19000122
Medicina Universitaria. 2020;22(1):15-20 www.medicinauniversitaria.org (http://creativecommons.org/licenses/by-nc-nd/4.0/). 
a functional disability and variable loss of autonomy in daily life activities, protracting the need for day-to-day assistance ${ }^{5}$. The recovery phase following a hip fracture is not only a challenging process for older adults but also informal caregivers (hereafter referred to as "caregivers") as well. Becoming a caregiver demands comprehension toward the patient and changes in the relationship between the care recipient and his/her relative and in the latter's lifestyle. The caregiver's ability to successfully adapt to these factors beyond the acute injury period directly impacts the patient's prognosis ${ }^{6}$. Recognizing the caregivers' socioeconomic context and caregiving skills may allow the development of specific strategies to enhance the rehabilitation process and lessen the relatives' burden ${ }^{5,7}$. To adapt to this incipient reality, we need to enrich our understanding of family caregiving to elders with fall-related hip fractures to reduce the social and economic costs associated with the rehabilitation process $^{8}$. Therefore, through this study, we aim to describe the sociodemographic characteristics and evaluate the caregiving abilities of informal caregivers of patients aged 65 years or older hospitalized for fall-related hip fractures in a Northeast Mexican sample.

\section{Materials and methods}

\section{Study design}

We conducted a cross-sectional study from March 2018 to February 2019 at the "Dr. José Eleuterio González" University Hospital of the Universidad Autónoma de Nuevo León, an academic tertiary care hospital in Monterrey, Mexico. Relatives that provided informal care to hospitalized elderly patients diagnosed with fall-related hip fractures were invited to participate. The Ethics in Research Committee of the University Hospital approved the study protocol before the study's beginning. All enrolled subjects provided their verbal informed consent before approval from the aforementioned committee.

\section{Recruitment and evaluation}

Relatives of patients aged 65 years or older admitted to our Orthopedic Unit for fall-related hip fractures were eligible to participate. The patient's age, gender, and diagnosis were obtained from medical records. Relatives were required to answer a sociodemographic questionnaire, and the scale to measure the caregiving ability of caregivers, a Likert scale designed by Barre$\mathrm{ra}^{6}$. Relatives of patients with the previous hip fractures or care home residents were excluded from the study.

\section{Hip fracture}

Fracture of the proximal femur down to $\approx 5 \mathrm{~cm}$ below the lower border of the small trochanter was the definition used to diagnose a hip fracture ${ }^{1,9}$. Identification of hip fracture cases was made through the daily medical census that indicated fracture location according to the International Classification of Diseases, $10^{\text {th }}$ Revision's codes: S72.0 (fracture of neck of femur), S72.1 (pertrochanteric fracture), S72.2 (subtrochanteric fracture), and S72.9 (Fracture of femur, and part unspecified) along with the patient's gender, age, length of stay, and secondary diagnoses ${ }^{10}$. The use of code S72.9 was included only in cases where analysis of medical records and radiology indicated that the location of the lesion was in the proximal femur.

\section{Informal caregiving}

We defined "informal caregiver" as an individual, usually a family member, without professional preparation for caregiving who provided unpaid care to someone with whom they have a personal relationship. The main tasks for caregivers of elders with fall-related hip fractures are related to filling the injury-related functional limitations and providing support for the rehabilitative treatment ${ }^{8,11-13}$.

\section{Sociodemographic factors}

Baseline sociodemographic factors included both patient and caregiver's age and gender. Caregivers were asked to specify a place of residence, education, marital status, family ties with the patient, number of offspring, and whether or not they were religious practitioners, had an active social life, or performed regular physical activity, as well as their smoking history and alcohol use. Socioeconomic questions comprised work status, monthly household income (based on the Social Work Department's tabulator), and primary source of income. In addition to these, the patient's discharge placement and caregiver's total sleep hours were also gathered.

\section{Measuring the caregiving ability of caregivers}

To evaluate caregiving abilities and attitude toward the role, we used the instrument "Caregiving ability of family caregivers of individuals with chronic disease," developed by Barrera et al. at the Universidad Nacional de 
Table 1. Care recipients' and caregivers' gender and mean age

\begin{tabular}{|l|c|c|}
\hline Care recipients' & $\#$ & $\%$ \\
\hline Gender & \multicolumn{2}{|c|}{} \\
\hline Male & 12 & 23.5 \\
Female & 39 & 76.5 \\
\hline Mean age & \multicolumn{2}{|c|}{82.41 years } \\
\hline Caregivers' & $\#$ & $\%$ \\
\hline Gender & \multicolumn{2}{|c|}{} \\
\hline Male & 5 & 9.8 \\
\hline Female & 46 & 90.2 \\
\hline Mean age & \multicolumn{2}{|c|}{50.39 years } \\
\hline
\end{tabular}

Colombia $^{6,14}$. The aforementioned scale is a self-applied 42-item instrument that evaluates the relationship between the patient and the caregiver, the caregiver's empathy and changes in the caregiver's lifestyle. The reliability of the instrument according to the index of internal consistency for Cronbach's alpha coefficient method in the total qualification was 0.82 , with findings for every subdivision being relation 0.61 , comprehension 0.81 , and modification of life $0.41^{14}$. The scale was self-applied by the caregiver in the presence of a member of the research team, who was able to answer questions if needed.

\section{Data analysis}

Gathered data were collected in a database for analysis using the SPSS software package for statistical analysis to obtain traditional descriptive statistics for quantitative variables, determining frequencies, and prevalence. Analysis of the instrument "Caregiving ability of family caregivers of individuals with chronic disease" was done through measures of central tendency (mean, media, and mode), measures of dispersion (range), and standard deviation.

\section{Results}

\section{Sample characteristics}

A total of 51 patients and caregivers were identified and recruited. Care recipients' mean age was 82.41 years, and $76.5 \%$ were women; all of them were living at home before the injury. Caregivers in this sample tended to be women (90.2\%), had an average age of 50.39 years (range, 28-84), and were mostly married $(74.5 \%)$ (Table 1). Concerning the educational level, $82.4 \%$ of caregivers had middle school diplomas or less. Regarding the caregiver's relation to the patient, $60.8 \%$ of caregivers were first-degree relatives (offspring,
Table 2. Caregivers' sociodemographic characteristics

\begin{tabular}{|c|c|c|}
\hline$n=51$ & $\#$ & $\%$ \\
\hline $\begin{array}{l}\text { Education } \\
\text { No education } \\
\text { Primary education } \\
\text { Secondary education } \\
\text { High school }\end{array}$ & $\begin{array}{c}1 \\
19 \\
22 \\
9\end{array}$ & $\begin{array}{c}2 \\
37.3 \\
43.1 \\
17.6\end{array}$ \\
\hline $\begin{array}{l}\text { Marital status } \\
\text { Single } \\
\text { Married } \\
\text { Consensual union } \\
\text { Separated } \\
\text { Divorced } \\
\text { Widowed }\end{array}$ & $\begin{array}{c}3 \\
34 \\
4 \\
4 \\
3 \\
3\end{array}$ & $\begin{array}{r}5.9 \\
66.7 \\
7.8 \\
7.8 \\
5.9 \\
5.9\end{array}$ \\
\hline $\begin{array}{l}\text { Relation to patient } \\
\text { First-degree relative } \\
\text { Second-degree relative }\end{array}$ & $\begin{array}{l}31 \\
20\end{array}$ & $\begin{array}{l}60.8 \\
39.2\end{array}$ \\
\hline $\begin{array}{l}\text { Caregiver's offspring } \\
\text { No children } \\
\text { One child } \\
\text { Two children } \\
\text { Three children } \\
\text { Four or more children }\end{array}$ & $\begin{array}{c}5 \\
5 \\
12 \\
8 \\
21\end{array}$ & $\begin{array}{r}9.8 \\
9.8 \\
23.5 \\
15.7 \\
41.2\end{array}$ \\
\hline $\begin{array}{l}\text { Religion } \\
\text { Yes } \\
\text { No }\end{array}$ & $\begin{array}{l}37 \\
14\end{array}$ & $\begin{array}{l}72.5 \\
27.5\end{array}$ \\
\hline $\begin{array}{l}\text { Social life } \\
\text { Active } \\
\text { Inactive }\end{array}$ & $\begin{array}{l}27 \\
24\end{array}$ & $\begin{array}{l}52.9 \\
47.1\end{array}$ \\
\hline $\begin{array}{l}\text { Place of residence } \\
\text { Monterrey's metropolitan area } \\
\text { State's rural area } \\
\text { Other state }\end{array}$ & $\begin{array}{c}47 \\
3 \\
1\end{array}$ & $\begin{array}{c}92.2 \\
5.9 \\
2\end{array}$ \\
\hline $\begin{array}{l}\text { Patient's post-discharge location } \\
\text { With caregiver } \\
\text { Not with caregiver }\end{array}$ & $\begin{array}{l}32 \\
19\end{array}$ & $\begin{array}{l}62.7 \\
37.3\end{array}$ \\
\hline $\begin{array}{l}\text { Monthly income (MXN) } \\
<\$ 1,942 \\
\$ 1,942-3,885 \\
\$ 3,886-7,771 \\
\$ 7,772 \text { or more }\end{array}$ & $\begin{array}{l}10 \\
11 \\
17 \\
13\end{array}$ & $\begin{array}{l}19.6 \\
21.6 \\
33.3 \\
25.5\end{array}$ \\
\hline $\begin{array}{l}\text { Main source of income } \\
\text { Own salary } \\
\text { Spouse's salary } \\
\text { Pension } \\
\text { Social assistance } \\
\text { Other }\end{array}$ & $\begin{array}{c}18 \\
26 \\
2 \\
3 \\
2\end{array}$ & $\begin{array}{c}35.3 \\
51 \\
3.9 \\
5.9 \\
3.9\end{array}$ \\
\hline $\begin{array}{l}\text { Substance use among caregivers } \\
\text { Only tobacco } \\
\text { Only alcohol } \\
\text { Tobacco and alcohol } \\
\text { None }\end{array}$ & $\begin{array}{c}4 \\
5 \\
3 \\
39\end{array}$ & $\begin{array}{r}7.8 \\
9.8 \\
5.9 \\
76.5\end{array}$ \\
\hline $\begin{array}{l}\text { Physical activity } \\
\text { Active } \\
\text { Inactive }\end{array}$ & $\begin{array}{l}15 \\
36\end{array}$ & $\begin{array}{l}29.4 \\
70.6\end{array}$ \\
\hline
\end{tabular}

sibling, or spouse), and $39.2 \%$ were second-degree or non-blood relatives (grandchildren, aunts, nephews/ 
Table 3. Findings from the scale to measure the caregiving ability of caregivers

\begin{tabular}{|l|c|c|c|c|c|c|}
\hline \multirow{2}{*}{ Type of caregiving ability } & \multicolumn{7}{|c|}{$\mathbf{n = 5 1}$} \\
\cline { 2 - 8 } & Mean & SD & Minimum score & Maximum score & Mode & Median \\
\hline Relation & 62.47 & 8.55 & 40 & 79 & 58 & 64 \\
\hline Comprehension & 57.82 & 8.05 & 33 & 68 & 62 & 60 \\
\hline Modification of life & 23.52 & 3.58 & 13 & 31 & 172 & 148 \\
\hline Total ability & 143.8 & 17.27 & 86 & 148 \\
\hline
\end{tabular}

SD: standard deviation.

nieces, and cousins) (Table 2). The vast majority of the caregivers (92.2\%) lived in the Monterrey Metropolitan Area, $5.9 \%$ lived in the state's rural area, and $2.0 \%$ lived in foreign states. The patient's post-discharge location was planned to be the caregiver's house in $62.7 \%$ of cases (Table 2). Religious practice was reported by $72.5 \%$, and $52.9 \%$ reported engagement in social activities; physical activity was regular in only $29.4 \%$ of caregivers. Monthly income was below $\$ 1,942$ Mexican pesos (MXN) for $19.6 \%$ of caregivers and between $\$ 1,942$ and $\$ 3,885$ for $21.6 \%$ of them. A household income of at least $\$ 7,772$ was reported by $25.5 \%$ of caregivers, which represents almost 3 times the Mexican minimum wage in 2018. Spouse's salary (51\%) and own salary $(35.3 \%)$ were the main sources of income for caregivers (Table 2). The use of alcohol and/or tobacco was denied by $76.5 \%$ of the subjects. Caregivers' average total sleep time was $6.67 \mathrm{~h} / \mathrm{night}$.

Analysis of the scale to measure the caregiving ability of caregivers showed an average score of caregiving abilities of 143.80 out of 188 possible points, with a standard deviation of 17.275 and a median of 148.00 . The highest score was 172.00 points, and the lowest was 86.00 points, where a higher score meant better caregiving abilities. Sub-analysis of the three components of the scale indicated the following (Table 3):

- Relation: An average of 62.47 with a standard deviation of 8.55 and scores ranging from 40 to 79 points, with a mode of 58 and median of 64 .

- Comprehension: An average of 57.82 with a standard deviation of 8.05 and scores ranging from 33 to 68 points, with a mode of 62 and median of 60 .

- Modification of life: An average of 23.51 with a standard deviation of 3.58 and scores ranging from 13 to 31 points, with a mode of 25 and median of 24 .

\section{Discussion}

The results from our study reveal a state of socioeconomic vulnerability and a lack of readiness to provide care in relatives of elders who suffer hip fractures. It is important to note that this research should be considered as an initial contribution to the creation of specific interventions for Mexican caregivers of patients with fall-related hip fractures. Our findings contribute to the acquaintance of the specific characteristics of Mexican caregivers, of which there is insufficient data, ${ }^{8,15}$. In comparison to similar studies, our population's mean age was higher, was also composed predominantly of women, but had a lower educational level,12,13,16. Consistent with previous findings, females were more likely than males to provide informal care to their older relatives; it has been reported that women provide better caregiving abilities and more assistance in personal care tasks ${ }^{8}$. Multiple hypotheses to explain gender gaps and kinship in caregiving suggest that the choice of caregiver follows a hierarchical pattern within family members, with the spouse usually being the primary caregiver $^{8}$. Nonetheless, daughters were the primary caregivers in the majority of our population, which may be linked to cultural and gender-role beliefs about filial obligations ${ }^{16,17}$. Caring for elder parents is central to the Hispanic culture, where there is a strong sense of obligation to reciprocate the care they previously received ${ }^{18}$. Care provided by daughters has been reported to reduce the probability of having a decline in the functional activities of older adults, although informal care does not influence the survival rate or health decline in fall-injured elders ${ }^{8}$.

The sudden conversion of a relative into a caregiver can be an overwhelming task that demands a broad number of adjustments that range from providing physical assistance to financial, household, and family dynamic changes ${ }^{5}$. Caregiving responsibilities by themselves may affect other members of the caregiver's family, due to changes in the environment that favor the patient in the household ${ }^{5,8}$. In our sample, $90.2 \%$ reported having one or more offspring, which suggests increased family duties with the recently acquired role and 
redistribution of the caregiver's attention; brief family interventions can benefit the adaptive process ${ }^{5,18,19}$.

Although new caregivers may anticipate during the period immediately succeeding the acute event that the fracture will become a turning point in their lives, predicting the economic burden caregiving represents may be difficult 5,19 . From the fracture's treatment to the transition of care from hospital to home and the rehabilitation process, adequate care is often achieved at the expense of the family's financial health ${ }^{20}$. Even though the vast majority of our population lived in Nuevo León, the state with the lowest poverty index in Mexico, $94.1 \%$ of our sample reported monthly incomes below $\$ 11,290.80$ Mexican pesos, considered an indicator of poverty by National Council for the Evaluation of Social Development Policy ${ }^{21}$. Therefore, it can be assumed that caregivers of elders with fall-related hip fractures will face significant financial difficulties in achieving a successful recovery process.

Analyses of our sample revealed shortened sleep duration (Mean $=6.67 \mathrm{~h} /$ night) in relatives at the time of the evaluation; no studies were found on the relative's sleep quality before or after caring for a patient with a hip fracture. Taking into consideration that poor sleep quality and its negative impact on caregivers and patients have long been described, sleep disturbances in caregivers before the hip fracture may have a positive predictive value of future problems in caregiving abilities, burnout, and adverse outcomes for the dyad ${ }^{22}$.

The average score of the measurement of caregivers' abilities for providing care to hip-fractured patients revealed the possibility that relatives overvalued these abilities at the beginning of their new role, a phenomenon widely described in prior studies ${ }^{19}$. The latter could have both positive and negative impacts on caregiving. First, a positive attitude toward acquired chores and changes in daily routine can have a benign impact on recovery and rehabilitation, lessening the impact of socioeconomic vulnerabilities ${ }^{23,24}$. On the other hand, an overestimation of the caregivers' capacities and an associated underestimation of the magnitude of the incoming burden could be a risk factor for adverse outcomes 23,25 .

This study has some limitations. The patient's condition and the stress of a hospital setting could have influenced the subjects' responses to the scale to measure the caregiving ability of caregivers. Furthermore, the scale has not been validated into a Mexican-Spanish version, which may have led to difficulties understanding or appreciation of Colombian colloquialisms. Another limitation is that the cohort of subjects studied was almost all from the same geographical area and socioeconomic background, so it may not be representative of the heterogeneity of the Mexican population.

Taking into account that informal caregiving inevitably demands significant changes in the caregiver's life that range from adjustments in family dynamics to reduced participation in the labor force and increased household expenses, it is necessary to meticulously evaluate the relative's willingness to become a caregiver and attitude toward caregiving ${ }^{5,7,8,19}$. Despite the significant modifications that occur with caregiving chores, assessment by the health providers of the relatives' knowledge, understanding, or proficiency of the tasks they are expected to perform is not routinely done ${ }^{26}$.

\section{Conclusions}

Our study offers a perspective of the caregivers' sociodemographic and economic context, along with an evaluation of their caregiving abilities in the clinical situation of hip fracture patients. We, therefore, believe that insufficient knowledge of the recovery process after hip fractures and poorly coordinated transitions between care sites represent important obstacles that can be aggravated by the relatives' lack of social and economic readiness to face this burden and their attitude toward becoming a caregiver. Monetary costs and health risks for caregivers must be taken into account by the medical team. Achieving a trade-off between caregiving responsibilities and self-care may be possible when both patient and caregiver are adequately informed of the severity and prognosis of fall-related hip fractures and provided with tailored training, thus decreasing the potential complications associated with the socioeconomic vulnerability of our population.

\section{Funding}

The authors declare than they did not receive funding from any private or public organizations for the completion of this research.

\section{Conflicts of interest}

The authors deny the existence of conflicts of interest related to the execution of the present study.

\section{Acknowledgments}

We thank the Department of Orthopedics and Traumatology and the Department of Psychiatry for the assistance provided during our research project. 


\section{Ethical disclosures}

Protection of human and animal subjects. The authors declare that no experiments were performed on humans or animals for this study.

Confidentiality of data. The authors declare that they have followed the protocols of their work center on the publication of patient data.

Right to privacy and informed consent. The authors have obtained the written informed consent of the patients or subjects mentioned in the article. The corresponding author is in possession of this document.

\section{References}

1. Parker MJ. Hip fractures in the elderly. Surgery. 2010;28:483-8.

2. Lovato-Salas F, Luna-Pizarro D, Oliva-Ramírez SA, Flores-Lujano J, Núñez-Enríquez JC. Prevalencia de fracturas de cadera, fémur y rodilla en la unidad médica de alta especialidad hospital de traumatología y ortopedia "Iomas verdes" del instituto mexicano del seguro social. Acta Ortop Mex. 2015;29:13-20.

3. INEGI. Perfil Sociodemográfico de Adultos Mayores. Vol. 1. Censo de Población y Vivienda; 2014. [cited 2018 Jun]. Available from: http://internet.contenidos.inegi.org.mx/contenidos/Productos/prod_serv/contenidos/ espanol/bvinegi/productos/censos/poblacion/2010/perfil_socio/adultos/702825056643.pdf

4. Johansson H, Clark P, Carlos F, Oden A, McCloskey EV, Kanis JA. Increasing age- and sex-specific rates of hip fracture in Mexico: a survey of the Mexican institute of social security. Osteoporos Int. 2011:22:2359-64.

5. Nahm ES, Resnick B, Orwig D, Magaziner J, Degrezia M. Exploration of informal caregiving following hip fracture. Geriatr Nurs. 2010;31:254-62.

6. Blanco-Sánchez JP. Validación de una escala para medir la habilidad de cuidado de cuidadores. Aquichan. 2014;14:351-63.

7. Bentler SE, Liu L, Obrizan M, Cook EA, Wright KB, Geweke JF, et al. The aftermath of hip fracture: discharge placement, functional status change, and mortality. Am J Epidemiol. 2009;170:1290-9.

8. Trujillo AJ, Mroz TA, Piras C, Angeles G, Tran N. Caregiving and elderly health in Mexico. Int J Health Serv. 2012;42:667-94

9. Parker M, Johansen A. Hip fracture. BMJ. 2006;333:27-30.

10. Anagnostis P, Paschou SA, Goulis DG. Management of acute hip fracture. N Engl J Med. 2018;378:971-2.
11. Cameron JI, Chu LM, Matte A, Tomlinson G, Chan L, Thomas C, et al. One-year outcomes in caregivers of critically III patients. N Engl J Med. 2016;374:1831-41.

12. Giosa JL, Stolee P, Dupuis SL, Mock SE, Santi SM. An examination of family caregiver experiences during care transitions of older adults. Can J Aging. 2014;33:137-53.

13. Hounsell C, Johnson WJ, Levine ES, Stein R, Vuckovic N, Wagner ID, et al. Caregiving in the U.S. AARP Report; 2015.

14. Mercado M, Barrera L. Confiabilidad del instrumento "habilidad de cuidado de cuidadores de pacientes con enfermedades cronicas." Av Enferm. 2013;31:12-20.

15. Comisión Nacional de Arbitraje Médico. Tasa Intrahospitalaria de Fracturas de Cadera en Adultos de 65 Años o Más Ocurridas en los Hospitales de la Secretaría de Salud. Mexico: Comisión Nacional de Arbitraje Médico; 2017. [cited 2018 Jun]. Available from: http://www.conamed.gob. $\mathrm{mx} / \mathrm{gobmx} /$ boletin/pdf/boletin12/tasa_intrahospitalaria.pdf

16. Mendez-Luck CA, Kennedy DP, Wallace SP. Guardians of health: the dimensions of elder caregiving among women in a Mexico city neighborhood. Soc Sci Med. 2009;68:228-34.

17. Robles L, Pérez A. Expectativas sobre la obligación filial: comparación de dos generaciones en México. Rev Latinoam Cienc Soc Niñez Juv. 2012;10:527-40.

18. Evans BC, Belyea MJ, Coon DW, Ume E. Activities of daily living in Mexican American caregivers: the key to continuing informal care. J Fam Nurs. 2012;18:439-66.

19. Elli S, Contro D, Castaldi S, Fornili M, Ardoino I, Caserta AV, et al. Caregivers' misperception of the severity of hip fractures. Patient Prefer Adherence. 2018;12:1889-95.

20. Shyu YI, Chen MC, Wu CC, Cheng HS. Family caregivers' needs predict functional recovery of older care recipients after hip fracture. J Adv Nurs. 2010;66:2450-9.

21. National Council of Evaluation of Social Development Policies. La Pobreza Por Ingresos en México. Mexico: National Council of Evaluation of Social Development Policies; 2010. [cited 2018 Jun] Available from: https://www.coneval.org.mx/rw/resource/coneval/info_public/pdf_publicaciones/pobreza_ingresos_mexico_web.pdf

22. Byun $E$, Lerdal A, Gay CL, Lee KA. How adult caregiving impacts sleep: a systematic review. Curr Sleep Med Rep. 2016;2:191-205.

23. Liu HY, Yang CT, Cheng HS, Wu CC, Chen CY, Shyu YI. Family caregivers' mental health is associated with postoperative recovery of elderly patients with hip fracture: a sample in Taiwan. J Psychosom Res. 2015;78:452-8.

24. Saletti-Cuesta L, Tutton E, Langstaff D, Willett K. Understanding patient and relative/carer experience of hip fracture in acute care: a qualitative study protocol. Int J Orthop Trauma Nurs. 2017;25:36-41.

25. Malmgren RN, Törnvall RN, Jansson RN. Patients with hip fracture: experiences of participation in care. Int J Orthop Trauma Nurs. 2014:18:143-50.

26. Wolff JL, Feder J, Schulz R. Supporting family caregivers of older Americans. N Engl J Med. 2016;375:2513-5 